\title{
The White Paper: a framework for survival?
}

The re-organisation of the NHS by the new coalition government will, as well as affecting all our lives, attract widespread international interest. Is it possible, in adverse financial circumstances, to sustain an almost wholly state-funded health service, and if so, how? This interest will be sharpened by the inclusion of an 'outcomes framework' as one of the central components of the recent government White Paper ${ }^{1}$ - the Quality and Outcomes Framework (QOF) for general practice has been a subject of intense international attention $^{2}$ - together with a greatly increased emphasis on the role of GPs in commissioning services for patients.

The new NHS Outcomes Framework will be concerned with three 'domains of quality': the effectiveness of treatment and its effect on both clinical and patientreported outcomes; the safety of the treatment provided; and patients' broader experience of health care. Many of the proposals for reform, including pledges to put yet more money into the NHS, are to be underpinned by the 'release' of efficiency savings within the NHS (an unprecedented $£ 20$ billion by 2014) and an audacious target of cutting NHS management by $45 \%$.

The White Paper Equity and Excellence: Liberating the $\mathrm{NHS}^{+}$and the supporting Impact Assessment paper, Transparency in Outcomes - a Framework for the NHS, ${ }^{3}$ start with an admission that things are not as good as they could be. The 'amenable' (avoidable) mortality rates across the system are notably inferior to rates in many other countries. The top five countries, with their national spend on health as a percentage of GDP, are France (11.2\%), Japan (8.1\%), Spain (9\%), Australia $(9.1 \%$,) and Sweden (9.4\%). The UK, with standardised death rates one-quarter higher and a health spend of $8.7 \%$ of GDP, limps in at 16th place in the most recent league tables, for 2002-3. ${ }^{4}$ There is work to be done.

The White Paper proposes the abolition both of strategic health authorities and primary care trusts (PCTs) and, instead of the local health boards proposed by the Liberal Democrats before the election, plans to create around 500 GP commissioning consortia which will be responsible to a new NHS Commissioning Board. A new Department of Public Health will sit alongside a weakened Department of Health, and the role of Monitor and the Care Quality Commission as regulators of the new system will be strengthened, together with the oversight provided by local Healthwatch (Figure 1).

One of many difficulties with these policy documents, which perhaps unwisely adopt a 'diagnostic' terminology, is that although the signs of the disorder are fairly clearly described, the differential diagnosis and the pathophysiology are lost in rhetoric about patients needing to be at the very centre of health care (where have they been up till now?), empowerment, challenge, change, and endless choice. This lack of detail is to be corrected by a series of further papers to be published in the near future, but at present it simply makes some of the proposals appear facile and poorly thought through.

The freedom of patients to switch between GPs or to keep the same GP when they move house, for example, is not linked to a system of remuneration consistent with the public health role of primary care, or any recognition of the importance of personal and organisational continuity for many patients. The description of the means by which PCTs will be run down and commissioning consortia established is hazy, and the support structures that need to be in place to get primary care commissioning working, where in the past it has woefully failed to deliver, are only vaguely described in the supporting paper on commissioning. ${ }^{3}$

The proposals on paying for pharmaceuticals, based on an undefined notion of 'value-based pricing', are vague and there is almost nothing so far about the pressing need to ensure coherence and safety throughout the NHS by having a computer system that works.

Although the Quality, Innovation, Productivity and Prevention programme ${ }^{5}$ gets a mention, this White Paper misses perhaps the most important structural target of all, and that is the tribal relationship between primary and secondary care that has bedevilled funding and service delivery models in the NHS ever since it was established. What is required is joint needs assessment, planning, commissioning, and accountability across localities, undertaken by primary and secondary care working together, and well supported by public health specialists and high-quality

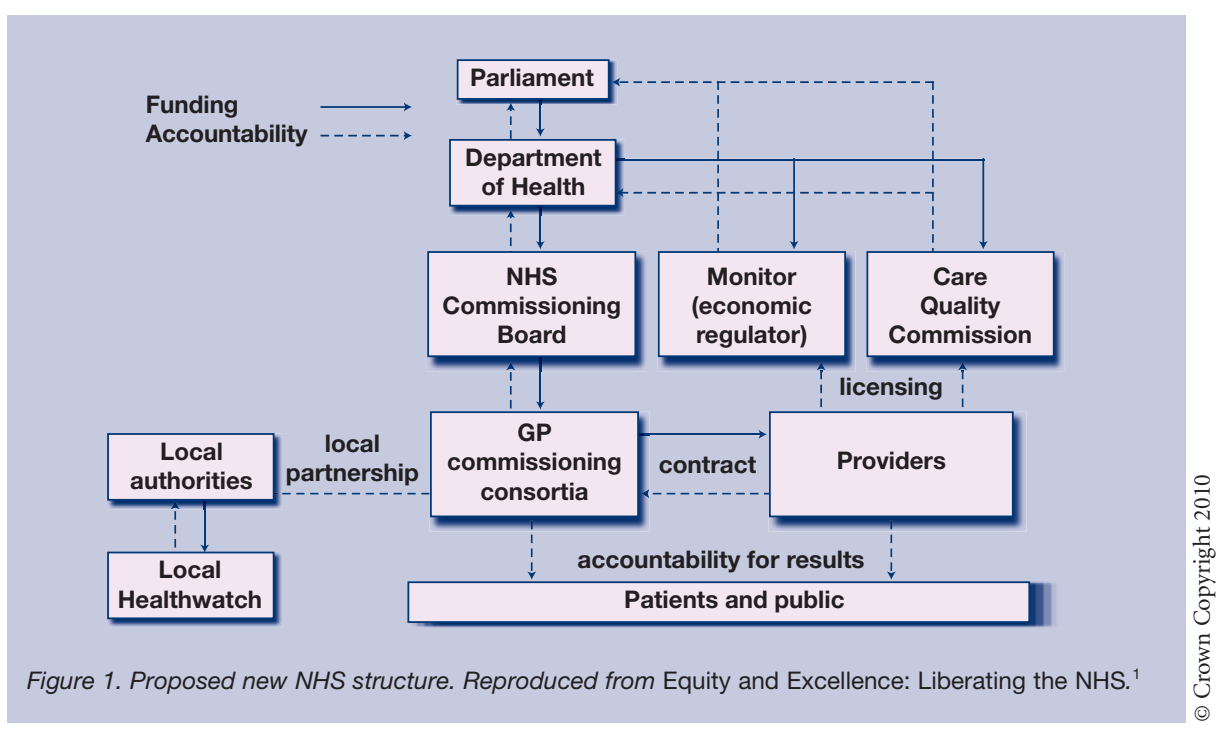


managers. This would not require a seismic change in the structure of the NHS to achieve. The paper on commissioning hardly mentions hospitals or specialities. Giving this appearance of writing consultants and hospitals out of the commissioning script is foolhardy.

Among a range of analyses of these proposals, the lack of evidence for the effectiveness of structural reform endemic in the NHS - perhaps stands out most starkly. ${ }^{6}$ The planning blight, uncertainty, and extra costs entailed in a major service redesign should not be underestimated. In his paean to the NHS on the occasion of its 60th birthday, Don Berwick, President of the Institute for Healthcare Improvement in Cambridge, Massachusetts, described the endless 'parade' of well-intentioned NHS reforms and warned:

'Stop restructuring ... Each change made sense, but the parade doesn't make sense. It drains energy and confidence from the workforce ... who learn not to take risks, but rather to hold their breaths and wait for the next change ... the time has come for stability, on the basis of which, paradoxically, productive change becomes easier and faster ..."7

If we have to change, rather than rearranging our limited present structures, why do we not look to and learn from more successful health systems in which a mix of private and public provision - including insurance schemes, means testing, payments for hospital and doctor visits, and co-payments for drug treatments lead to better patient health outcomes and greater patient satisfaction?

And this, of course, is the heart of the matter: through no fault of its own, the NHS has become unaffordable. Changes in disease epidemiology, population demography, medical technology, and healthcare delivery mean that western societies now have to find alternative ways to pay for health care. Protecting the NHS will force massive cuts in other government departments, such as education and social services, ${ }^{8}$ and will have an impact on state pensions provision.

President Obama appears to have attempted to re-distribute the responsibility for paying for health care in the US without tackling the perverse drivers behind skyrocketing healthcare costs, which are wired into the system. This new White Paper seems to be suggesting the reverse, by restructuring the service and ignoring the funding crisis. A bolder and more imaginative approach to health care is needed if the White Paper is to represent more than a blank cheque for another doomed NHS reorganisation.

\section{Roger Jones \\ Editor, BJGP}

\section{Provenance}

Freely submitted; not peer reviewed.

\section{REFERENCES}

1. Department of Health. The White Paper. Equity and excellence: liberating the NHS. Cm 7881. London:

Department of Health, 2010.

2. Campbell SM, Reeves D, Kontopantelis E, et al. Effects of pay for performance on the quality of primary care in England. N Engl J Med 2009; 361(4): 368-378.

3. Department of Health, Medical Directorate, Quality and Outcomes Policy. Liberating the NHS:

transparency in outcomes - a framework for the NHS London: Department of Health, 2010.

4. Nolte N, McKee CM. Measuring the health of nations: updating an earlier analysis. Health Aff (Millwood) 2008; 27(1): 58-71.

5. Department of Health. Implementing the Next Stage Review visions: the quality and productivity challenge. London: Department of Health, 2009.

6. Walshe K. Reorganisation of the NHS in England. BMJ 2010; 341: c3843.

7. Berwick DM. A transatlantic review of the NHS at 60. BMJ 2008; 337: a838.

8. Appleby J, Crawford R, Emmerson C. How cold will it be? Prospects for NHS funding 2011-17. London: King's Fund, 2009.

DOI: 10.3399/bjgp10X515322

\section{ADDRESS FOR CORRESPONDENCE}

\section{Roger Jones}

British Journal of General Practice, Royal College of General Practitioners, 1 Bow Churchyard, London, EC4M 9DQ. E-mail: journal@rcgp.org.uk 